\title{
(2) OPEN ACCESS \\ Levels of domain-specific physical activity at work, in the household, for travel and for leisure among 327789 adults from 104 countries
}

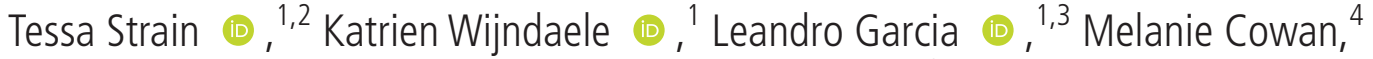 \\ Regina Guthold (1) , ${ }^{5}$ Soren Brage (1) , ${ }^{1}$ Fiona C Bull (1) ${ }^{6,7}$
}

${ }^{1}$ MRC Epidemiology Unit, University of Cambridge, Cambridge, UK

${ }^{2}$ Physical Activity for Health Research Centre, University of Edinburgh, Edinburgh, UK ${ }^{3}$ Centre for Public Health, Queen's University Belfast, Belfast, UK

${ }^{4}$ Department of

Noncommunicable Diseases, World Health Organization,

Geneva, Switzerland

${ }^{5}$ Maternal, Newborn, Child, and Adolescent Health and Ageing Department, World Health Organization, Geneva, Switzerland

${ }^{6}$ Department of Health Promotion, Division of Universal Health Coverage and Healthier Populations, World Health Organization, Geneva, Switzerland

${ }^{7}$ Physical Activity Unit, The University of Western Australia, Perth, Western Australia, Australia

\section{Correspondence to}

Dr Tessa Strain, MRC

Epidemiology Unit, University of Cambridge, Cambridge CB2 OQQ, UK;

tessa.strain@mrc-epid.cam. ac.uk

$S B$ and $F C B$ are joint senior authors.

Accepted 12 September 2020 Published Online First 22 October 2020

\begin{abstract}
Objective To compare the country-level absolute and relative contributions of physical activity at work and in the household, for travel, and during leisure-time to total moderate-to-vigorous physical activity (MVPA).
\end{abstract}

Methods We used data collected between 2002 and 2019 from 327789 participants across 104 countries and territories ( $n=24$ low, $n=34$ lower-middle, $n=30$ upper-middle, $n=16$ high-income) from all six World Health Organization (WHO) regions. We calculated mean min/week of work/household, travel and leisure MVPA and compared their relative contributions to total MVPA using Global Physical Activity Questionnaire data. We compared patterns by country, sex and age group (25-44 and 45-64 years).

Results Mean MVPA in work/household, travel and leisure domains across the 104 countries was 950 (IQR 618-1198), 327 (190-405) and 104 (51-131) min/ week, respectively. Corresponding relative contributions to total MVPA were $52 \%$ (IQR 44\%-63\%), 36\% (25\%-45\%) and $12 \%(4 \%-15 \%)$, respectively. Work/ household was the highest contributor in 80 countries; travel in 23; leisure in just one. In both absolute and relative terms, low-income countries tended to show higher work/household (1233 min/week, 57\%) and lower leisure MVPA levels (72 min/week, 4\%). Travel MVPA duration was higher in low-income countries but there was no obvious pattern in the relative contributions. Women tended to have relatively less work/household and more travel MVPA; age groups were generally similar.

Conclusion In the largest domain-specific physical activity study to date, we found considerable countrylevel variation in how MVPA is accumulated. Such information is essential to inform national and global policy and future investments to provide opportunities to be active, accounting for country context.

\section{INTRODUCTION}

The physical and mental health benefits of physical activity are well established, ${ }^{1-3}$ yet $27.5 \%$ of the global adult population do not reach the minimum recommended levels. ${ }^{4}$ The World Health Organization (WHO) member states agreed to a $15 \%$ reduction in physical inactivity levels by $2030^{2}$ but this is unlikely to be achieved, given current trajectories. ${ }^{4}$

Physical activity is a complex behaviour; however, opportunities to be active exist in several domains in life: at work, household or at school, for travel or during leisure time. Different domains may contribute to health in different ways. ${ }^{5}$ Understanding the composition of how and where people accumulate their activity has important implications for policy, clinical practice and future public health investments. Economic development and its associated technological, demographic and societal changes have the potential to influence the opportunities for activity across different settings. ${ }^{67}$ One way of investigating these patterns is by comparing domain-specific physical activity behaviour between countries at different stages of economic development.

Occupational physical activity is influenced by the country's urbanisation level and occupational structure, with more urbanised, service-dominated countries showing lower levels. ${ }^{8}$ Leisure activity levels appear to be higher in high compared with low-income countries, ${ }^{9}$ although even between highincome countries, levels of urbanisation and wealth seem to be positively associated with leisure activity prevalence. ${ }^{10}$ Active travel patterns are less clear by income group as high-income countries provide examples of both high and low levels. For instance, active travel accounts for half of all journeys in the Netherlands and Switzerland but only a quarter in the UK and California, ${ }^{11}$ suggesting differences in available transport infrastructure, social norms or both. This illustrates the complexity of the global perspective on domain-specific physical activity levels, something that has not been systematically researched.

Older age and female sex are known correlates of lower overall physical activity levels. ${ }^{12} 13$ While a number studies have shown differences in the absolute levels of domain-specific activity, ${ }^{14-16}$ few have explored how the relative contributions by age and sex differ. ${ }^{17} 18$ Understanding whether different at-risk subgroups rely on certain physical activity domains more than others is critical information for policy-makers to protect existing and promote new behaviours and to help reduce health inequalities.

This study uses the latest internationally comparable physical activity data to compare the absolute and relative contributions of physical activity at work and in the household, for travel and during leisure time to total moderate-to-vigorous physical activity (MVPA) for 104 countries across the spectrum of economic development. As a secondary aim, we also compared the domain-specific MVPA contributions by sex and age group.

\section{METHODS}

Data sources

We obtained the most recent individual-level survey data from 104 countries and territories (hereafter called countries) in which the WHO Global 
Physical Activity Questionnaire (GPAQ) was used. ${ }^{19}$ These included 94 surveys using the WHO STEPwise approach to noncommunicable disease surveillance (STEPS), ${ }^{20} 6$ from the WHO Study on global AGEing and adult health (SAGE), ${ }^{21}$ and 4 from public archives (see Acknowledgments and Data Availability statements for details).

The countries covered were from all six WHO regions: Africa $(n=37)$, Americas $(n=15)$, Eastern Mediterranean $(n=12)$, Europe $(n=8)$, South-East Asia $(n=8)$ and Western Pacific $(n=24)$. According to World Bank Income Classification (2020), ${ }^{22} 24$ were low, 24 were lower-middle, 30 were uppermiddle, and 16 were high-income countries (online supplemental file 1). These countries make up $71 \%$ of the global population in $2020 .^{23}$

In addition, an earlier STEPS survey was identified for four countries in the African region (Benin, Botswana, Malawi, Seychelles) for an exploratory analysis of domain-specific trends. These were countries within the same region, spanning all income classification groups, and with national data from two points in time with a minimum time gap of 5 years between them and the most recent time point within the last 5 years.

\section{Representativeness of data}

Survey sampling was designed to obtain a nationally representative $(n=90+4$ trend datasets) or a subnational $(n=14)$ sample. In the majority of cases, this was a stratified multistage clustered design but some of the subnational surveys or smaller islands used simple random, quota or interval sampling, or a census (online supplemental file 2). Sample weights were provided for 91 (+3 trend) surveys to adjust for unequal selection probabilities. These also adjusted for the oversampling of those $\geq 50$ years in the SAGE surveys, and normalised to population distributions of age, sex and in some cases region and ethnicity in the publicly available surveys.

Eight of the subnational surveys were urban only. For these, we imputed rural data and weighted them by national urbanrural prevalence to derive national estimates. In the urban-rural mixed subnational survey, we performed this weighting step with the data collected. The remaining five subnational surveys were analysed with no adjustment. Full methods are provided in online supplemental file 3 .

The analysis was limited to the common age-range across all surveys (25-64 years) for comparability reasons so the estimates presented in this paper are not official national statistics.

\section{Global Physical Activity Questionnaire}

We only included surveys which had used the WHO GPAQ. This instrument captures MVPA undertaken in a typical week at work (paid or unpaid, including household chores), for travel to and from places by walking or cycling, and during leisure time (including sports and fitness-enhancing activities). ${ }^{19}$ Work/household and leisure domains are split into moderate and vigorous intensity. Only MVPA undertaken in bouts of $10 \mathrm{~min}$ or more is reported, and participants are reminded not to report activities already included in an earlier answer. The GPAQ was translated into national languages, and back translated for quality assurance, and show-cards were used to provide culturally relevant examples of physical activities in each domain.

The GPAQ has shown comparable levels of validity to other self-report instruments across a variety of cultural settings. ${ }^{24-28}$ In the absence of domain-specific validity evidence, we estimated the Pearson's correlation coefficients for the associations between the country-level domain-specific MVPA (median min/ week) and indicators selected a priori (online supplemental file 4). These were work/household and the proportion of the workforce in the agricultural sector (males: $r=0.43$, females: $r=0.46$ ) and other occupations involving a high degree of manual labour (males: $r=0.47$, females: $r=0.48$ ); travel and the number of vehicle registrations per adult in the population $(r=-0.49)$; and leisure and the GINI measure of economic inequality across the population $(r=0.03)$, and the Human Development Index $(\mathrm{r}=0.27)$.

\section{Data processing}

The standard GPAQ data processing protocol was followed. ${ }^{19}$ Individuals reporting implausible ( $>16$ hours/day in one of the domains) or inconsistent (eg, no days but valid duration) were excluded. We considered moderate and vigorous intensity work/household and leisure physical activity separately for this step. We further excluded those with missing data in either the frequency or duration variables in any domain (online supplemental file 5). We calculated total weekly duration in minutes for each individual by multiplying the number of days and daily time variables for each domain and summing the totals. For the main analysis, we combined the moderate and vigorous components of work/household and leisure as reported. In a sensitivity analysis, we doubled the reported duration of vigorous intensity activity to reflect the physical activity guidelines that suggest $75 \mathrm{~min}$ of vigorous intensity activity provides comparable benefits to $150 \mathrm{~min}$ of moderate intensity activity. ${ }^{3}$

We estimated the absolute levels of domain-specific MVPA (min/week) at a country level, and by sex and age group (25-44 and 45-64 years) strata based on all those meeting the inclusion criteria. We calculated relative contributions at an individual level, and group-level arithmetic means were presented. Those who reported no MVPA across all domains could not provide any information to the relative contributions (online supplemental file 5). We described differences with reference to the World Bank Income Classification 2020. ${ }^{22}$ We estimated Pearson's correlation coefficients for the associations between the mean domain-specific MVPA and total MVPA at a country level. We performed the analyses in Stata V.16 (StataCorp) and produced the ternary plots in $\mathrm{R}$ Studio using the ggtern ${ }^{29}$ and tricolore packages. ${ }^{30}$

\section{Public involvement}

The experiences of data collectors informed the development of the GPAQ, ${ }^{24}$ and assisted in the cultural and language adaptations made for each country.

\section{RESULTS}

We included data from 327789 individuals aged 25-64 years from 104 countries collected between 2002 and 2019. The prevalence of meeting the WHO physical activity guidelines ranged between $36 \%$ and $98 \%$, and the proportion reporting zero min/ week of total MVPA ranged between 1\% and 51\% (table 1).

\section{Absolute levels of domain-specific activity}

The distributions of the reported weekly durations of work/ household, travel and leisure MVPA were highly skewed for all countries; the mode was almost always zero min/week (online supplemental file 6). The country-level means for the domains were 950 (IQR 618-1198), 327 (190-405) and 104 (51-131) $\mathrm{min} / \mathrm{week}$, for work/household, travel and leisure time, respectively (table 2, figure 1, online supplementary file 6). Mean work/ household MVPA in low-income countries was almost twice that 
Table 1 Descriptive characteristics of the survey samples of participants aged 25-64 years from 104 countries

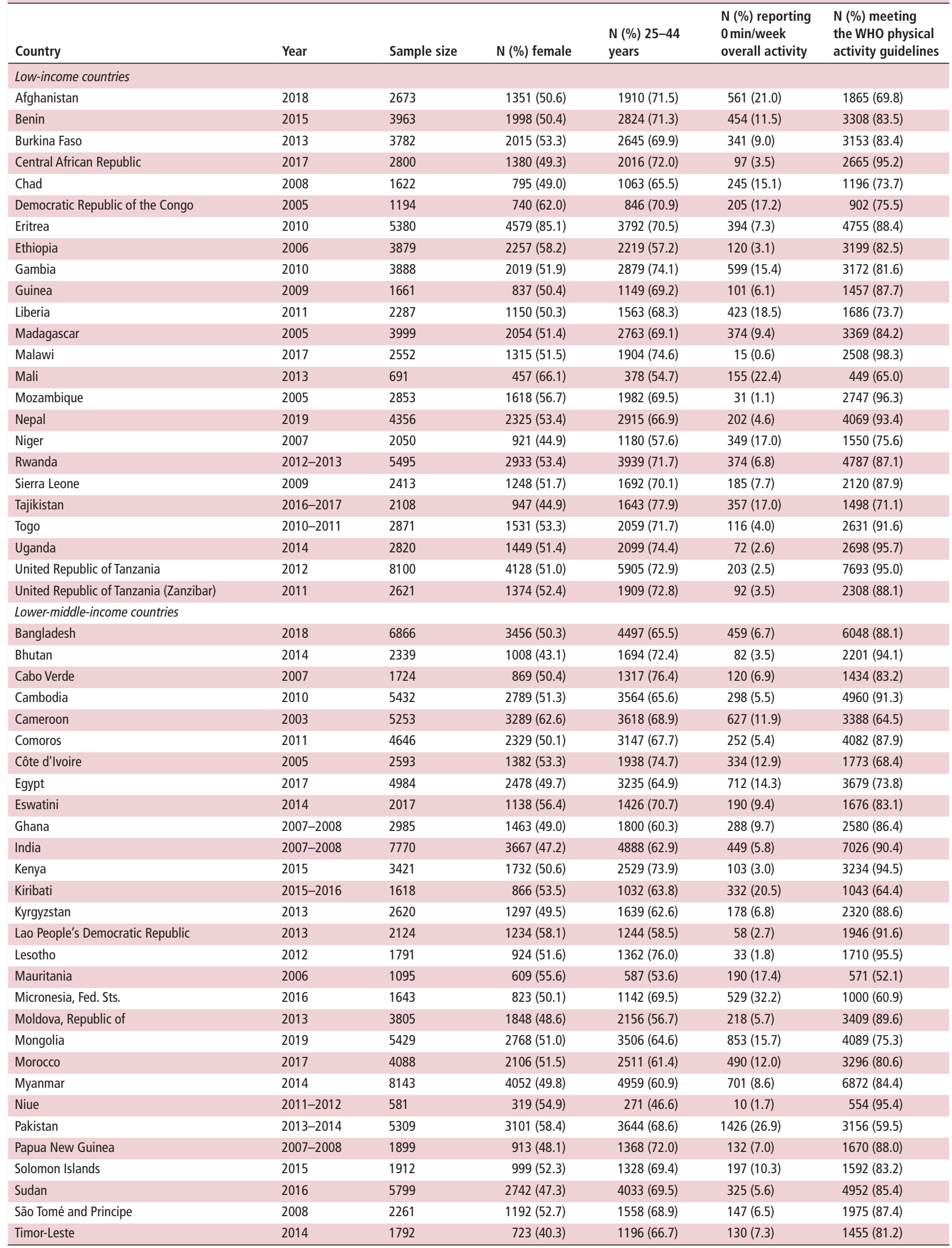




\section{Original research}

Table 1 Continued

\begin{tabular}{|c|c|c|c|c|c|c|}
\hline Country & Year & Sample size & N (\%) female & $\begin{array}{l}\mathrm{N}(\%) \text { 25-44 } \\
\text { years }\end{array}$ & $\begin{array}{l}\mathrm{N}(\%) \text { reporting } \\
0 \mathrm{~min} / \text { week } \\
\text { overall activity }\end{array}$ & $\begin{array}{l}\mathrm{N}(\%) \text { meeting } \\
\text { the WHO physical } \\
\text { activity guidelines }\end{array}$ \\
\hline Tokelau & 2014 & 439 & $240(54.6)$ & $261(59.5)$ & $28(6.3)$ & $386(87.9)$ \\
\hline Vanuatu & 2011 & 4457 & $2343(52.6)$ & $3031(68.0)$ & $91(2.0)$ & 4177 (93.7) \\
\hline Viet Nam & 2015 & 3116 & 1605 (51.5) & $1866(59.9)$ & $556(17.9)$ & 2302 (73.9) \\
\hline West Bank and Gaza Strip & $2010-2011$ & 5105 & $2536(49.7)$ & $3580(70.1)$ & $1336(26.2)$ & $3050(59.7)$ \\
\hline Zambia & 2017 & 2550 & $1253(49.1)$ & $1916(75.1)$ & $139(5.5)$ & $2276(89.3)$ \\
\hline \multicolumn{7}{|c|}{ Upper-middle-income countries } \\
\hline Algeria & $2016-2017$ & 5566 & $2789(50.1)$ & $3677(66.1)$ & $741(13.3)$ & $4193(75.3)$ \\
\hline American Samoa & 2004 & 2015 & $1010(50.1)$ & $1354(67.2)$ & $941(46.7)$ & 845 (41.9) \\
\hline Armenia & 2016 & 1825 & $877(48.1)$ & $1046(57.3)$ & $283(15.5)$ & $1437(78.8)$ \\
\hline Azerbaijan & 2017 & 2322 & $1196(51.5)$ & $1343(57.8)$ & 269 (11.6) & $1889(81.3)$ \\
\hline Belarus & 2016-2017 & 4203 & $2178(51.8)$ & $2162(51.4)$ & $301(7.2)$ & $3682(87.6)$ \\
\hline Botswana & 2014 & 2688 & $1343(49.9)$ & $1939(72.2)$ & $270(10.0)$ & $2118(78.8)$ \\
\hline Brazil & 2013-2014 & 21942 & $11692(53.3)$ & $12721(58.0)$ & 6105 (27.8) & $14509(66.1)$ \\
\hline China & 2008-2010 & 9055 & $4574(50.5)$ & $4235(46.8)$ & $1187(13.1)$ & $7130(78.7)$ \\
\hline Cook Islands & 2013-2015 & 1064 & $536(50.4)$ & $636(59.8)$ & $169(15.8)$ & $800(75.2)$ \\
\hline Ecuador & 2018 & 3620 & 1879 (51.9) & $2041(56.4)$ & $304(8.4)$ & $2977(82.2)$ \\
\hline Fiji & 2011 & 2325 & $1173(50.4)$ & $1369(58.9)$ & $144(6.2)$ & $1973(84.9)$ \\
\hline Gabon & 2009 & 1958 & $1144(58.4)$ & $1269(64.8)$ & $231(11.8)$ & $1418(72.4)$ \\
\hline Georgia & 2016 & 3346 & $1743(52.1)$ & $1726(51.6)$ & $322(9.6)$ & $2776(83.0)$ \\
\hline Grenada & 2010-2011 & 1030 & $502(48.8)$ & $674(65.4)$ & $184(17.8)$ & $733(71.1)$ \\
\hline Guyana & 2016 & 2051 & 1017 (49.6) & $1254(61.1)$ & $391(19.1)$ & $1444(70.4)$ \\
\hline Iraq & 2015 & 3036 & 1505 (49.6) & $1981(65.2)$ & $853(28.1)$ & $1615(53.2)$ \\
\hline Jordan & 2019 & 4350 & $2325(53.5)$ & $2979(68.5)$ & $476(10.9)$ & $3250(74.7)$ \\
\hline Lebanon & 2017 & 1426 & $764(53.6)$ & $885(62.1)$ & $726(50.9)$ & $548(38.4)$ \\
\hline Libya & 2009 & 3460 & $1740(50.3)$ & $2692(77.8)$ & $783(22.6)$ & $2194(63.4)$ \\
\hline Maldives & 2011 & 1222 & $615(50.3)$ & $911(74.6)$ & $320(26.2)$ & $756(61.9)$ \\
\hline Marshall Islands & 2002 & 1806 & $1100(60.9)$ & $1271(70.4)$ & $751(41.6)$ & $997(55.2)$ \\
\hline Mexico & 2009-2010 & 1324 & $717(54.1)$ & $906(68.4)$ & $192(14.5)$ & $962(72.6)$ \\
\hline Nauru & 2015-2016 & 1031 & $534(51.8)$ & $719(69.8)$ & $267(25.9)$ & $617(59.8)$ \\
\hline Russian Federation & 2007-2010 & 2306 & $1284(55.7)$ & $1248(54.1)$ & $115(5.0)$ & $2146(93.1)$ \\
\hline Saint Lucia & 2012 & 1673 & $1039(62.1)$ & $853(51.0)$ & $268(16.0)$ & $1226(73.3)$ \\
\hline Samoa & 2013 & 1412 & $681(48.2)$ & $901(63.8)$ & $118(8.4)$ & $1216(86.1)$ \\
\hline South Africa & 2007-2008 & 2447 & $1291(52.8)$ & $1476(60.3)$ & $915(37.4)$ & $1374(56.2)$ \\
\hline Sri Lanka & 2014-2015 & 4321 & $2184(50.6)$ & $2436(56.4)$ & $837(19.4)$ & 3029 (70.1) \\
\hline Tonga & 2017 & 3201 & 2068 (64.6) & $1940(60.6)$ & $826(25.8)$ & $1920(60.0)$ \\
\hline Tuvalu & 2015 & 935 & $489(52.3)$ & $590(63.1)$ & $141(15.1)$ & $689(73.6)$ \\
\hline \multicolumn{7}{|l|}{ High-income countries } \\
\hline Anguilla & 2016 & 1347 & $695(51.6)$ & $782(58.0)$ & $235(17.4)$ & $1014(75.3)$ \\
\hline Bahamas & 2011-2012 & 1617 & $806(49.8)$ & 998 (61.7) & $524(32.4)$ & $955(59.0)$ \\
\hline Barbados & 2007 & 934 & $489(52.4)$ & $566(60.6)$ & $207(22.2)$ & $599(64.1)$ \\
\hline British Virgin Islands & 2009 & 1065 & $486(45.6)$ & $572(53.7)$ & $189(17.8)$ & $780(73.3)$ \\
\hline Brunei Darussalam & 2015-2016 & 2761 & $1418(51.4)$ & $1793(64.9)$ & $318(11.5)$ & $2050(74.2)$ \\
\hline Cayman Islands & 2012 & 1266 & $624(49.3)$ & $800(63.2)$ & $222(17.5)$ & $922(72.8)$ \\
\hline Chile & 2016-2017 & 3831 & $1919(50.1)$ & $2108(55.0)$ & $668(17.4)$ & $2699(70.4)$ \\
\hline French Polynesia & 2010 & 2862 & $1379(48.2)$ & $1815(63.4)$ & $225(7.9)$ & $2440(85.3)$ \\
\hline Korea, Rep. & 2018 & 4038 & $1987(49.2)$ & $1938(48.0)$ & $1274(31.6)$ & $1866(46.2)$ \\
\hline Kuwait & 2014 & 3160 & $1678(53.1)$ & $2170(68.7)$ & $1613(51.0)$ & $1131(35.8)$ \\
\hline Palau & 2016 & 1173 & $553(47.1)$ & $569(48.5)$ & $261(22.3)$ & $783(66.8)$ \\
\hline Qatar & 2012 & 2003 & $1006(50.2)$ & $1411(70.5)$ & $466(23.3)$ & $1182(59.0)$ \\
\hline Seychelles & 2013-2014 & 1239 & $618(49.8)$ & 716 (57.8) & $59(4.7)$ & 1007 (81.3) \\
\hline Trinidad and Tobago & 2011 & 2151 & $1113(51.7)$ & $1287(59.8)$ & $613(28.5)$ & $1285(59.8)$ \\
\hline USA & 2017-2018 & 3628 & 1855 (51.1) & $1800(49.6)$ & $726(20.0)$ & $2504(69.0)$ \\
\hline Uruguay & 2013-2014 & 2090 & $1091(52.2)$ & $1157(55.4)$ & $302(14.5)$ & $1613(77.2)$ \\
\hline
\end{tabular}

Cameroon, Central African Republic, Chad, Côte d'Ivoire, Democratic Republic of the Congo, Ethiopia, Gabon, Guinea, Madagascar, Maldives, Mali, Mauritania, Micronesia Fed. Sts. and Pakistan are subnational surveys. Total sample size is unweighted, all other N/proportions are weighted when sample weights have been provided. Meeting the WHO physical activity guidelines is defined as $\geq 150 \mathrm{~min}$ of moderate intensity activity per week, or $\geq 75$ min of vigorous intensity activity per week, or $\geq 600 \mathrm{MET}$-min/week. 
Table 2 Mean domain-specific min/week, relative contributions and rank order for the 104 countries, by income classification, sex and age group

\begin{tabular}{|c|c|c|c|c|c|c|c|c|c|}
\hline & \multirow[b]{2}{*}{ All countries } & \multicolumn{4}{|c|}{ World Bank income classification } & \multirow[b]{2}{*}{ Men } & \multirow[b]{2}{*}{ Women } & \multirow[b]{2}{*}{ 25-44 years } & \multirow[b]{2}{*}{ 45-64 years } \\
\hline & & Low & Lower-middle & Upper-middle & High & & & & \\
\hline Number of countries & 104 & 24 & 34 & 30 & 16 & 104 & 104 & 104 & 104 \\
\hline \multicolumn{10}{|l|}{$\begin{array}{l}\text { Mean min/week } \\
\text { (IQR) }\end{array}$} \\
\hline Work/household & $\begin{array}{l}950 \\
(618-1198)\end{array}$ & $\begin{array}{l}1233 \\
(915-1600)\end{array}$ & $\begin{array}{l}1069 \\
(735-1424)\end{array}$ & $\begin{array}{l}740 \\
(505-923)\end{array}$ & $\begin{array}{l}668 \\
(468-924)\end{array}$ & $\begin{array}{l}1137 \\
(805-1501)\end{array}$ & $\begin{array}{l}777 \\
(457-1036)\end{array}$ & $\begin{array}{l}986 \\
(667-1268)\end{array}$ & $\begin{array}{l}883 \\
(523-1149)\end{array}$ \\
\hline Travel & $\begin{array}{l}327 \\
(190-405)\end{array}$ & $\begin{array}{l}499 \\
(348-609)\end{array}$ & $\begin{array}{l}320 \\
(260-386)\end{array}$ & $\begin{array}{l}287 \\
(188-338)\end{array}$ & $\begin{array}{l}158 \\
(110-184)\end{array}$ & $\begin{array}{l}373 \\
(237-470)\end{array}$ & $\begin{array}{l}284 \\
(147-365)\end{array}$ & $\begin{array}{l}328 \\
(182-410)\end{array}$ & $\begin{array}{l}323 \\
(204-418)\end{array}$ \\
\hline Leisure & $\begin{array}{l}104 \\
(51-131)\end{array}$ & $\begin{array}{l}72 \\
(35-109)\end{array}$ & $\begin{array}{l}97 \\
(43-124)\end{array}$ & $\begin{array}{l}118 \\
(52-157)\end{array}$ & $\begin{array}{l}143 \\
(108-193)\end{array}$ & $\begin{array}{l}141 \\
(71-184)\end{array}$ & $\begin{array}{l}70 \\
(27-99)\end{array}$ & $\begin{array}{l}120 \\
(59-158)\end{array}$ & $\begin{array}{l}76 \\
(30-102)\end{array}$ \\
\hline \multicolumn{10}{|l|}{$\begin{array}{l}\text { Mean relative } \\
\text { contribution to total } \\
\text { MVPA (IQR) }\end{array}$} \\
\hline Work/household & $\begin{array}{l}52.3 \\
(44.3-63.3)\end{array}$ & $\begin{array}{l}57.3 \\
(54.1-68.0)\end{array}$ & $\begin{array}{l}57.2 \\
(48.8-68.8)\end{array}$ & $\begin{array}{l}47.5 \\
(41.6-56.7)\end{array}$ & $\begin{array}{l}43.7 \\
(39.3-54.8)\end{array}$ & $\begin{array}{l}53.0 \\
(46.0-63.3)\end{array}$ & $\begin{array}{l}51.6 \\
(42.0-65.4)\end{array}$ & $\begin{array}{l}52.7 \\
(44.7-64.4)\end{array}$ & $\begin{array}{l}51.6 \\
(43.7-63.9)\end{array}$ \\
\hline Travel & $\begin{array}{l}36.0 \\
(25.3-45.3)\end{array}$ & $\begin{array}{l}38.3 \\
(28.0-39.4)\end{array}$ & $\begin{array}{l}34.6 \\
(24.5-42.7)\end{array}$ & $\begin{array}{l}39.7 \\
(29.0-48.8)\end{array}$ & $\begin{array}{l}28.5 \\
(19.6-34.1)\end{array}$ & $\begin{array}{l}33.8 \\
(24.1-42.3)\end{array}$ & $\begin{array}{l}38.3 \\
(26.3-47.7)\end{array}$ & $\begin{array}{l}34.4 \\
(24.2-42.2)\end{array}$ & $\begin{array}{l}39.0 \\
(27.6-48.0)\end{array}$ \\
\hline Leisure & $\begin{array}{l}11.7 \\
(4.4-15.4)\end{array}$ & $\begin{array}{l}4.4 \\
(2.5-5.8)\end{array}$ & $\begin{array}{l}8.2 \\
(3.7-10.8)\end{array}$ & $\begin{array}{l}12.8 \\
(8.3-15.7)\end{array}$ & $\begin{array}{l}27.8 \\
(20.5-33.3)\end{array}$ & $\begin{array}{l}13.2 \\
(5.9-17.7)\end{array}$ & $\begin{array}{l}10.1 \\
(2.6-14.2)\end{array}$ & $\begin{array}{l}12.9 \\
(4.7-18.1)\end{array}$ & $\begin{array}{l}9.3 \\
(2.9-12.4)\end{array}$ \\
\hline \multicolumn{10}{|l|}{ Rank order (n) } \\
\hline$W>T>L$ & 70 & 20 & 29 & 17 & 4 & 68 & 65 & 71 & 64 \\
\hline $\mathrm{W}>\mathrm{L}>\mathrm{T}$ & 10 & 0 & 1 & 1 & 8 & 13 & 6 & 12 & 8 \\
\hline$L>T>W$ & 1 & 0 & 0 & 0 & 1 & 1 & 0 & 0 & 1 \\
\hline $\mathrm{L}>\mathrm{W}>\mathrm{T}$ & 0 & 0 & 0 & 0 & 0 & 0 & 4 & 2 & 0 \\
\hline $\mathrm{T}>\mathrm{L}>\mathrm{W}$ & 2 & 0 & 0 & 1 & 1 & 3 & 2 & 3 & 2 \\
\hline $\mathrm{T}>\mathrm{W}>\mathrm{L}$ & 21 & 4 & 4 & 11 & 2 & 19 & 27 & 16 & 29 \\
\hline
\end{tabular}

L, leisure; T, travel; W, work/household.

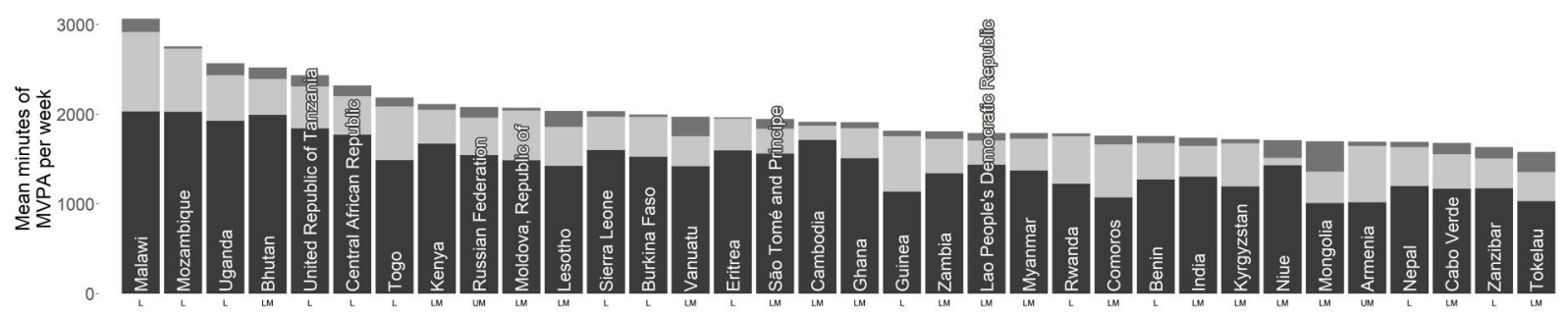

3000
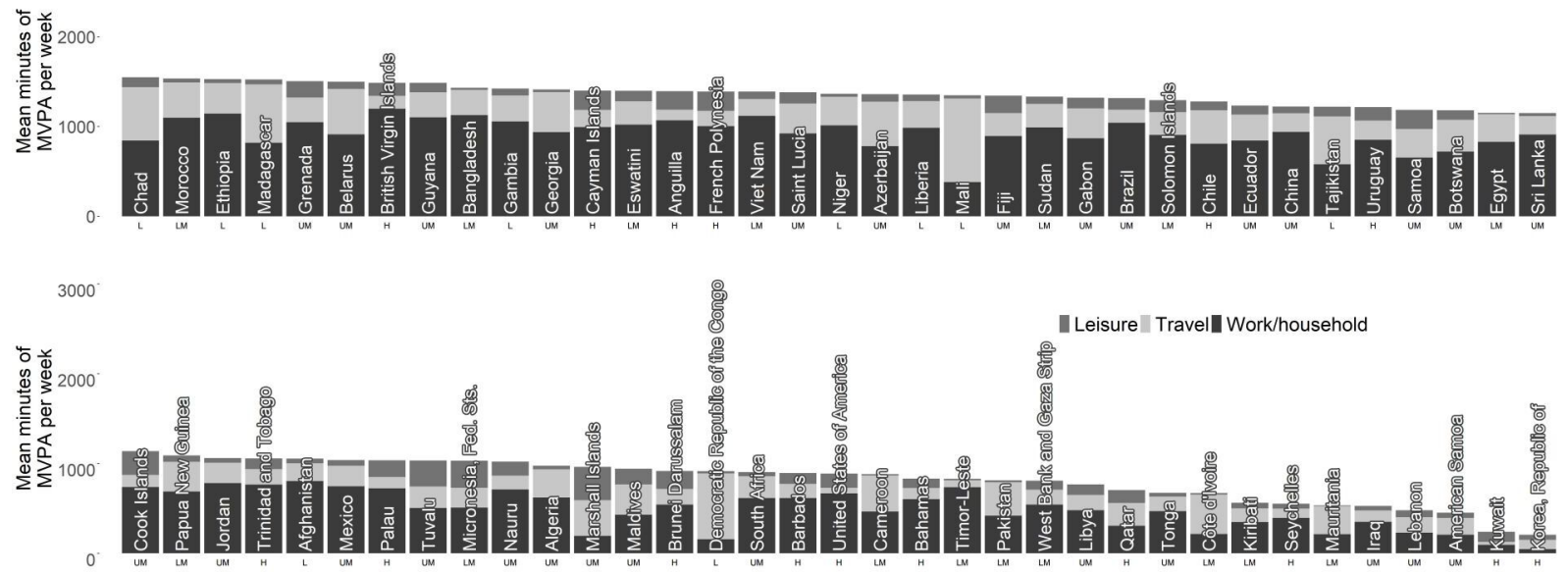

Figure 1 The mean total min/week of moderate-to-vigorous physical activity (MVPA) by domain, across 104 countries, ordered by total MVPA. $\mathrm{H}=$ high-income, $\mathrm{LM}=$ lower-middle-income, UM=upper-middle-income, L=low-income according to the World Bank Classification 2020. Cameroon, Central African Republic, Chad, Côte d'Ivoire, Democratic Republic of the Congo, Ethiopia, Gabon, Guinea, Madagascar, Maldives, Mali, Mauritania, Micronesia Fed. Sts. and Pakistan are subnational surveys. See online supplemental file 6 for the mean and median domain-specific min/week. 


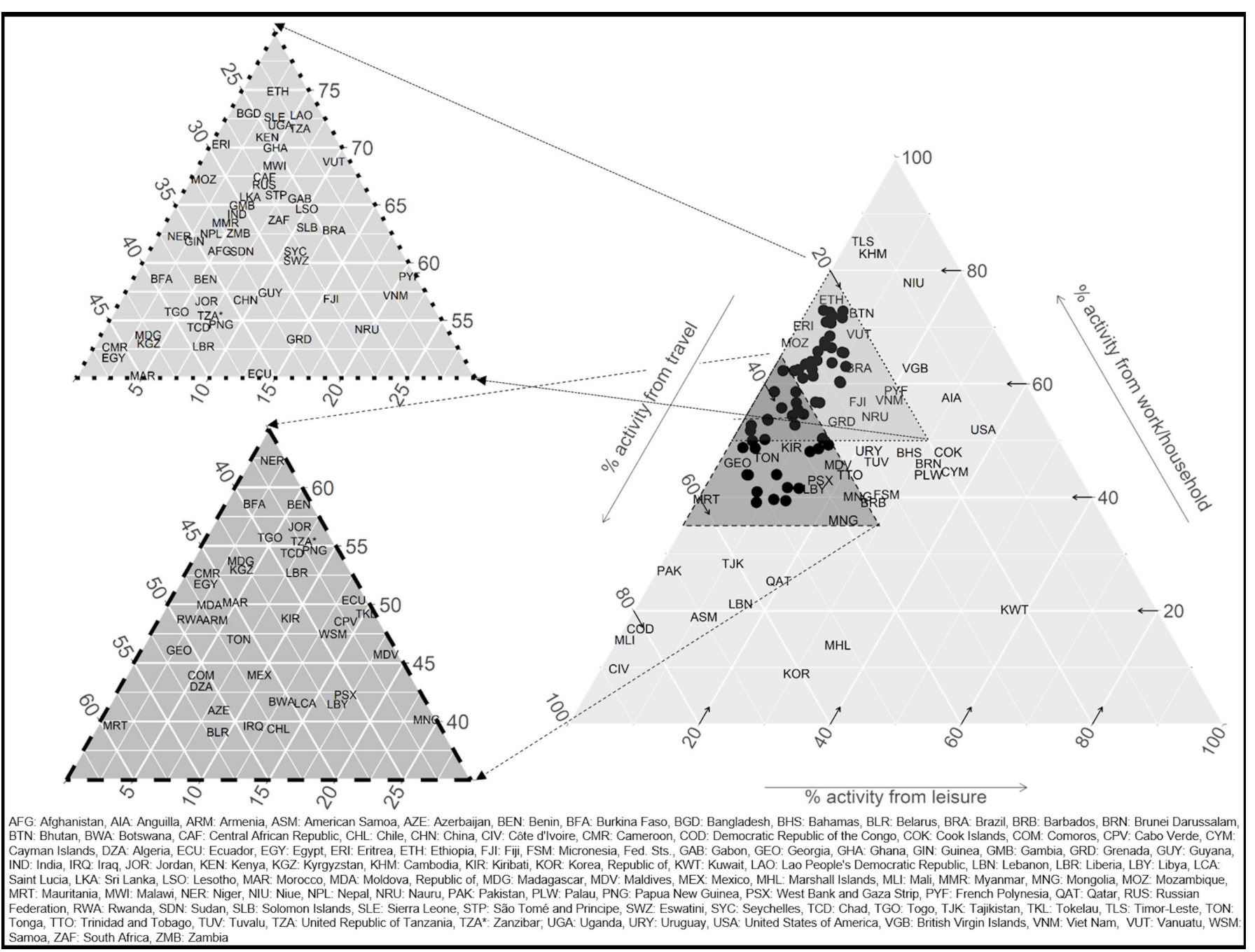

Figure 2 Ternary plot of the relative contributions of work/household, travel and leisure moderate-to-vigorous physical activity (MVPA) to total MVPA. Mean relative contributions should be read following the direction of the arrows for each axis. For example, in the USA, relative contributions are $52 \%$ from work/household, 11\% from travel, 37\% from leisure. Cameroon, Central African Republic, Chad, Côte d'Ivoire, Democratic Republic of the Congo, Ethiopia, Gabon, Guinea, Madagascar, Maldives, Mali, Mauritania, Micronesia Fed. Sts. and Pakistan are subnational surveys.

of high-income countries (1233 vs $668 \mathrm{~min} /$ week). However, the reverse was seen for mean leisure MVPA (72 vs $143 \mathrm{~min} /$ week). Travel MVPA was approximately three times higher in lowincome versus high-income countries (499 vs $158 \mathrm{~min} /$ week). We found a very strong correlation between work/household MVPA and total MVPA $(\mathrm{r}=0.95)$ at the country level. The correlation was 0.58 for travel and 0.04 for leisure MVPA.

\section{Relative contributions of domain-specific activity to total MVPA}

The 47946 individuals who reported $0 \mathrm{~min} /$ week of total MVPA did not contribute to the relative analyses (denominator of zero; online supplemental file 5). Based on the remaining 279843 , the mean contribution of work/household MVPA to total MVPA was 52\% (IQR 44\%-63\%); the respective means for travel and leisure were $36 \%(25 \%-45 \%)$ and $12 \%(4 \%-15 \%$; table 2$)$. Work/household domain was the largest contributor to total MVPA in 80 of the 104 countries, and 70 of these had travel as the second-largest contributor. Travel was the largest contributor in 23 countries, and leisure was dominant in only one.

There was a tendency towards higher contributions of leisure MVPA in high-income countries (mean of 28\% compared with $4 \%, 8 \%$, and $13 \%$ in low, lower-middle, and uppermiddle-income countries, respectively; table 2 , figure 2 , online supplementary files 7 and 8). The mean contributions of work/ household MVPA in low and lower-middle-income countries were $57 \%$, but were $44 \%-47 \%$ for upper-middle and highincome countries. The contribution of travel to total MVPA did not follow a clear pattern by World Bank income group.

Doubling the duration of vigorous intensity activity (ie, $1 \mathrm{~min}$ of vigorous physical activity $=2$ min of moderate intensity physical activity) in the work/household and leisure domain obviously influenced the absolute durations but did not affect the relative contributions in a meaningful way. This was because those individuals reporting high levels of work/household vigorous intensity activity were already obtaining close to $100 \%$ of their MVPA in this domain and so further increases in the absolute durations did not shift the balance of the domain contributions. This conversion therefore had limited influence on the countrylevel mean relative contributions which varied by a maximum of 2 percentage points for all domains and the highest contributing domain only changed in five countries.

There was a tendency towards greater travel and lower work/ household contributions among women compared with men, 


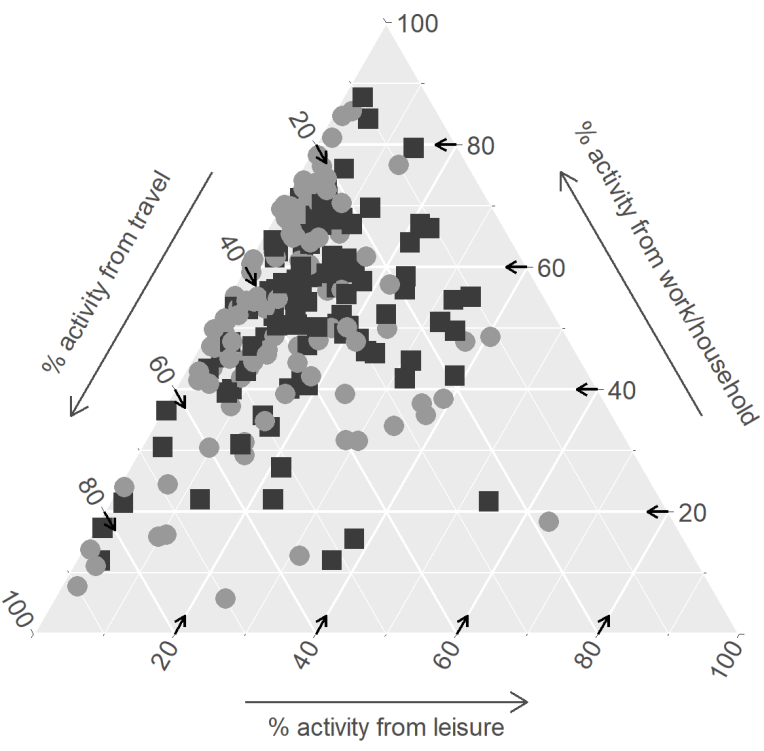

Sex

Female

Male

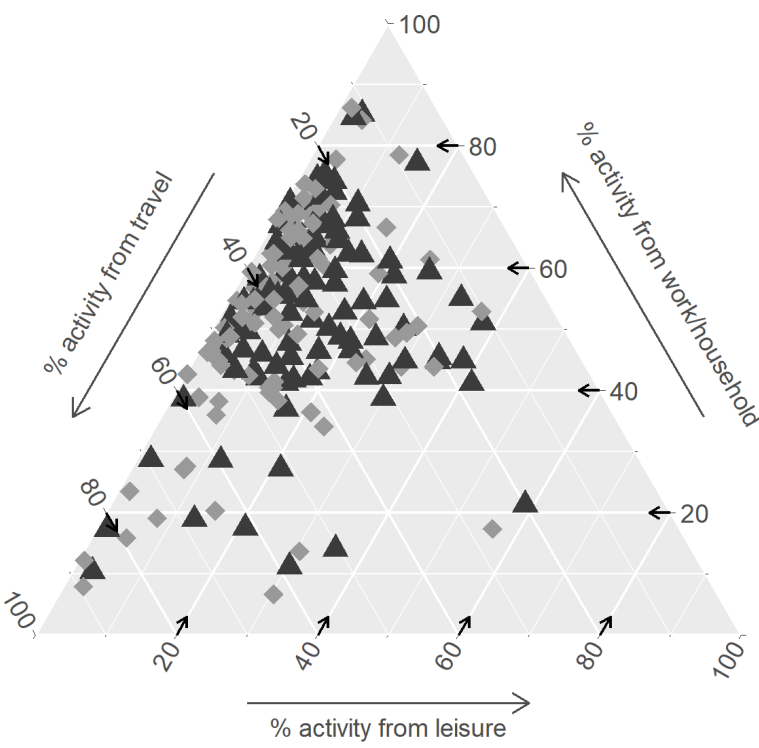

Age group $\quad 25-44$ years $\Delta$ 45-64 years

Figure 3 Ternary plots of the relative contributions of work/household, travel and leisure moderate-to-vigorous physical activity (MVPA) to total MVPA by sex and age group. Mean relative contributions should be read following the direction of the arrows for each axis. Cameroon, Central African Republic, Chad, Côte d'Ivoire, Democratic Republic of the Congo, Ethiopia, Gabon, Guinea, Madagascar, Maldives, Mali, Mauritania, Micronesia Fed. Sts. and Pakistan are subnational surveys.

judged by the means and rank ordering of the domains (table 2 , figure 3, online supplementary file 9). Twenty-eight countries had a different ordering of the domain-specific contributions and 42 countries had at least one domain where the relative contributions differed by over 10 percentage points. Differences were more apparent in high-income and upper-middle-income countries.

The variations between 25-44 and 45-64 year olds were not as pronounced as the sex differences. Only 15 countries had over10 percentage point difference in the relative contributions of a domain, and no clear pattern was apparent in terms of the domains in which these occurred (table 2, figure 3, online supplementary file 9). Twelve of these 15 countries were classified as upper-middle and high-income.

\section{Exploratory analysis of domain-specific trends}

We conducted exploratory analysis of trends using a subsample of data from four African countries $(n=25749)$, spanning the income classifications (figure 4). The results show considerable heterogeneity in the directions and magnitudes of the changes in domain-specific MVPA over time, even within income classifications.

\section{DISCUSSION}

Main findings

This study is the largest comparison of country-level domainspecific physical activity to date, including 372789 individuals from 104 countries. We found the work and household domain to be the highest contributor to total MVPA levels in threequarters of countries. Travel was the second-largest contributor for all but one of the remaining countries, and was rarely the lowest contributor. There was a trend towards greater contributions of MVPA through work/household in lower income countries, and higher contributions of physical activity through leisure in high-income countries. This pattern was suspected but is shown quantitatively for the first time in a large sample of representative surveys across multiple regions. There were differences in the relative contributions of the domains by sex and age group within countries, with a tendency towards greater differences in upper-middle and high-income countries.

\section{Comparison with previous results}

Previous national-level domain-specific analyses have been focused on specific regions, for example, Africa, ${ }^{31}$ South America, ${ }^{16}$ Asia-Pacific, ${ }^{14}$ while other cross-national studies have investigated the proportions reporting a certain threshold of domain-specific activity (eg, 0, 10, $150 \mathrm{~min} /$ week) which limit comparisons with the present results. ${ }^{151632}$ Our results extend the range of comparisons to be cross continental allowing greater comparisons between different World Bank income classifications, and show the relative importance of the domains in addition to the absolute values. Although high-income countries are relatively under-represented in our analyses, the 16 that are included act as helpful comparators to contrast the dominance of work/household-related activity and the low prevalence of leisure activity among many low and middle-income countries. Comparisons in total and domain-specific physical activity by country-level and individual-level income groups is an important yet under-researched area of global physical activity surveillance. However, it is clear that factors beyond income level and economic development, such as cultural and historical aspects, likely play a role in explaining differences between countries.

Our exploratory analysis of changes over time within domains is an indicator of this complexity. Some but not all countries showed a decline in the work/household domain, a feature that was expected as the epidemiological transition is accompanied by a shift away from manual labour and increased access to labour-saving technology in the home. ${ }^{8}$ The variations seen in the work/household and travel domain trajectories is likely to be explained by differences in countries' socioeconomic 


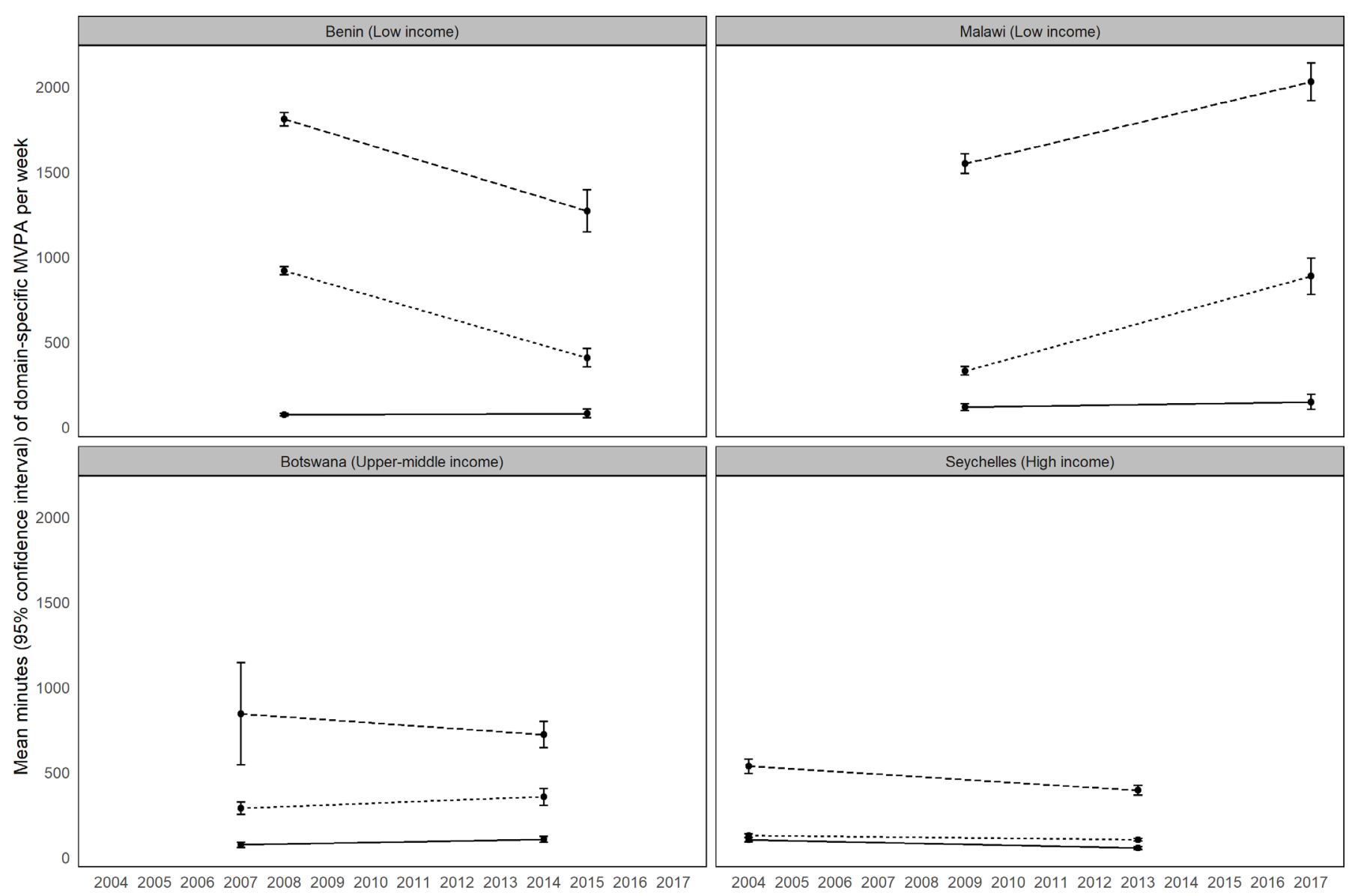

Domain - Leisure -... Travel --- Work/Household

Figure 4 An exploratory analysis of trends in the domain-specific moderate-to-vigorous physical activity (MVPA) in four African countries. World Bank Income 2020 classifications used.

circumstances, level of urbanisation and rates of development. Urbanisation and uptake of digital technologies as well as other cultural, environmental and social factors influence the opportunities for increasing levels of participation in the different domains in different ways. These results indicate the importance of further research on this topic with a larger set of comparable data. It is also a reminder that while global comparisons can identify broad patterns, this needs to be coupled with a local understanding of the context in order to develop appropriate policies and interventions.

Building on previous research that has shown lower levels of overall MVPA among women compared with men across the majority of countries worldwide, ${ }^{412}$ we showed that the domain composition also varies. The profile for women, at least in high-income and upper-middle-income countries, had a slightly higher contribution of travel and lower contribution of work/ household. These results provide a more nuanced understanding of how physical activity varies by sex.

We did not identify any notable differences in the relative contributions of the activity domains between 25-44 and 45-64 year olds, although where differences were found, they tended to be in upper-middle and high-income countries. Research from UK samples indicated that the greater shifts in domain-related contributions occur after 65 years, that is, around the age of retirement. ${ }^{17} 18$
Implications of the findings

These results can inform the development of interventions and policies aimed at increasing overall physical activity levels as called for by the 2018 Global Action Plan on Physical Activity. ${ }^{2}$ The high contribution of work/household activity for many low and middleincome countries is important for a number of reasons. First, it identifies a reliance on this domain for meeting activity recommendations that may not persist as countries develop economically. ${ }^{78}$ Policy action is necessary to ensure that alternative types of activity are available and affordable to those who might otherwise decrease their activity levels as consequence of such societal and economic changes. The travel domain is an obvious area of focus as our results show that it already is an important contributor to overall levels across all countries. Policies and infrastructure development that promote walking and cycling would also support efforts to reduce air pollution and carbon emissions to combat climate change as set out in the Sustainable Development Goals. ${ }^{33}$ Second, these data stress the importance of assessing all domains of physical activity, since solely concentrating on the leisure domain (as has often been the case $\mathrm{e}^{34}$ ) would grossly misrepresent, and for many populations underestimate, overall physical activity prevalence. ${ }^{35}$ Third, if domain-specific activity were to show any differential health benefits, as recently debated, ${ }^{36}$ mapping absolute and relative profiles of domain-specific activity is critical for estimations of global disease burden. 


\section{Limitations}

Methodological limitations include the unavailability of sampling weights for 13 countries and the necessity of using imputation methods to account for urban-rural variations when including subnational samples. Our aim was to be as inclusive as possible with the available data. Nonetheless, imputation likely increases the error regarding the representativeness of these estimates, over and above that of the national sampling. To maintain comparability between samples, we restricted the age range to $25-64$ year olds. For these reasons, the descriptive statistics of overall activity and the proportions meeting the guidelines do not replace any official national statistics and are presented for context only. The novel estimates of the domain-specific relative contributions are valid in the context of this paper, but further work is necessary to generate official statistics that include adults of all ages, and the multitude of other national survey data collected using alternative questionnaires.

The validity of domain-specific GPAQ estimates has not been evaluated against an appropriate criterion, such as a domain log. ${ }^{37}$ Some have raised concerns about the implausible work/household values. ${ }^{38}$ Inaccurate recall, social desirability and activity misclassification are possible sources of error. In lieu of such a validity study, the correlations presented between the work/household and travel domains and the selected country-level indicators provide tentative support for domain-specific analysis using GPAQ data. We believe the weaker results for the leisure domain are in part due to the number of countries with a median MVPA of zero min/week and the lack of specificity in the macro-economic indicators. In addition, the GPAQ states a minimum $10 \mathrm{~min}$ bout length, a requirement that is no longer included in the WHO physical activity guidelines. ${ }^{1}$ The inclusion of shorter bouts might alter the duration of reported activity across all domains, but it is difficult to predict which domains would be more affected as the magnitude of these increments is likely context specific. This would influence the relative contributions. Also, the GPAQ does not contain questions about light-intensity activity which is a major contributor to overall activity. ${ }^{39}$ It is likely that its inclusion would change the relative domain-specific results as well the absolute.

Finally, in the relative contribution analysis, we presented the arithmetic mean values (of individuals for each country, and of countries within income classifications). Although the scaled geometric mean is often used in compositional data, this was not an option when so many individuals reported $0 \mathrm{~min} /$ week in at least one domain. However, our analysis method is somewhat protected against individuals reporting very high values of domain-specific activity as the relative contributions were calculated at an individual level, before being summarised at a country level. This means a high value in one domain is limited to a maximum of $100 \%$ relative contribution. Of course, this does not protect against issues of differential validity between the domains, which is a plausible concern as even the ordering of questions can affect reporting. ${ }^{40}$ In the GPAQ, the work/ household domain is asked about first and all surveys used the same ordering. There is also the potential for cultural differences in the reporting as there are different interpretations of work/household, travel and leisure activity across populations. We were also unable to account for seasonal differences as surveys are often conducted within a short period of time that does not span all seasons.

\section{Future directions}

Filling in the data gaps will require wider adoption of the GPAQ in national surveys or harmonisation between different existing questionnaires. This would be pertinent for the European region as many countries have nationally representative data using alternative questionnaires. Nonetheless, it is rare in physical activity studies for the majority of data to be from low and middle-income countries and so this present work does provide an important perspective on the topic.

Future work could extend these methods to investigate subnational regional differences that others have shown to exist. ${ }^{41} 42$ Exploring variation by socioeconomic differences would also have utility, and require suitable harmonisation of indicators of socioeconomic position across nations.

We have also highlighted the need for analysis of trends in domain-specific data. As countries repeat their STEPS surveys, more comparable data will become available. In the meantime, efforts should be made to harmonise existing data.

Lastly, although the present study reflects the optimal analysis of currently available data, the advent of combined location and physical activity sensors may allow objective assessment of domain-specific activity in future research.

\section{Conclusion}

This study is the largest analysis of domain-specific physical activity to date comparing data from 104 countries. Activity at work/household is the main contributor to total MVPA levels, particularly in lower income countries. Leisure activity was the smallest contributor but was highest in high-income countries. Achieving the $15 \%$ decrease in global levels of physical inactivity by 2030 as outlined in the Global Action Plan on Physical Activity, ${ }^{2}$ and agreed by 194 Member States of $\mathrm{WHO}^{43}$ will require detailed understanding of the context in which people accumulate their physical activity, especially for countries currently undergoing rapid economic development and urbanisation. Across all nations, policy actions will need to align efforts to support and enable opportunities to be active in different domains according to the social, economic and demographic changes, population needs and local context.

What are the new findings?

- Physical activity in the domains of work and household, travel and leisure vary broadly across countries in both their absolute levels and relative contributions to total moderateto-vigorous physical activity (MVPA).

- Work/household MVPA provided the largest contribution in 80 of the 104 countries included in this study.

- Women tended to have relatively less work/household and more travel MVPA.

- Differences between 25-44 and 45-64 year olds were less apparent than differences between the sexes, but were most evident in high and upper-middle-income countries.

How might it impact on clinical practice in the near future?

- Clinicians and policy-makers alike should be aware that MVPA is accumulated across a variety of domains, and this varies across countries.

- Work/household is a dominant source of MVPA for many; this has implications for continuing to meet guidelines at the point of changing jobs or retirement.

- Women tended to have relatively lower contributions of work/household and more travel MVPA and this should be considered when tailoring behavioural advice. 
Acknowledgements The authors gratefully acknowledge the work of the STEPS survey coordinators: Dr Sayed Ataullah Saeedzai and Dr Said Habib Arwal (Afghanistan), Dr Djamila Nadir-Azirou (Algeria), Mr Asofa'afetai Maga (American Samoa), Dr Twyla Bradshaw-Richardson (Anguilla), Ms Tsagik Vardanyan and Ms Diana Andreasyan (Armenia), Dr Nabil Seyidov (Azerbaijan), Dr Delon Brennen (Bahamas), Prof Dr Baizid Khoorshid Riaz (Bangladesh), Dr Kenneth George (Barbados), Dr Vital Pisaryk (Belarus), Prof Dismand Stéphane Houinato (Benin), Dr Wangchuk Dukpa (Bhutan), Dr Heluf G Medhin (Botswana), Ms Ivy George (British Virgin Islands), Dr Lubna binti Haij Abdul Razak (Brunei Darussalam), Dr EstelleEdith Dabiré/Dembélé (Burkina Faso), Dr Irenita Soares (Cabo Verde), Dr Sophal Oum (Cambodia), Prof Alfred K Njamnshi (Cameroon), Dr Anna Matthews (Cayman Islands), Dr Max Roger Koula (Central African Republic), Mr Mathias Roger Djidina (Chad), Dr Mohamed Msaidie (Comoros), Mrs Mirella Mairi (Cook Islands), Dr Kouamelan Doua (Côte d'Ivoire), Prof Longo Mbenza (Democratic Republic of the Congo), Romina Costa Beltrán (Ecuador), Ministry of Health (Egypt), Dr. Goitom Mebrahtu Medhani (Eritrea), Dr. Lindiwe Tsabedze (Eswatini), Dr. Fikru Tesfaye (Ethiopia), Dr Isimeli Tukana (Fiji), Dr Merehau Mervin (French Polynesia), Dr Comlan Pearl Nsie Obame (Gabon), Mr Omar Badjie (Gambia), Ms Lela Sturua (Georgia), Ms Agnes Banfield (Grenada), Prof Naby Moussa Baldé (Guinea), Dr Kavita Singh (Guyana), Dr Husham J Abd Al-Badri (Iraq), NCD Directorate at the Ministry of Health (Jordan), Dr Joseph Mwangi Kibachio (Kenya), Mrs Eretii Timeon (Kiribati), Dr Rihab Alwotayan (Kuwait), Dr Roza Djakypova (Kyrgyzstan), Dr Manithong Vonglokham (Lao People's Democratic Republic), Ministry of Health (Lebanon), Dr Kabelo Mputsoe (Lesotho), Dr Peter L Clement (Liberia), Dr Omar Msalam (Libya), Dr Henri Fidele Marie Raharivohitra (Madagascar), Dr Kelias Msyamboza (Malawi), Mr Ubeydulla Thoufeeq (Maldives), Dr Diarra Nazoum (Mali), Dr Mailynn KoneliosLanginlur (Marshall Islands), Prof Mohamed Lemine Ba (Mauritania), Mr Marcus Samo (Micronesia, Fed. Sts.), Dr Galina Obreja (Moldova, Republic of), Dr Narantuya Davaakhuu (Mongolia), Dr Hicham El Berri (Morocco), Dr Carla MT Da Silva Matos (Mozambique), Dr Tint Swe Latt (Myanmar), Mr Don Kadir (Nauru), Dr Meghnath Dhimal and Mr Bihungum Bista (Nepal), Dr Moussa Habibou (Niger), Ms Grizelda Mokoia (Niue), Dr Huma Qureshi (Pakistan), Ministry of Health (Palau), Dr Lloyd Ipai and Ms Vicky Wari (Papua New Guinea), Dr Al Anoud Mohammed Al-Thani (Qatar), Mr Alypio Nyandwi (Rwanda), Dr Alina Jaime (Saint Lucia), CEO Ministry of Health (Samoa), Dr Lazaro Sousa (São Tomé and Principe), Dr Pascal Bovet (Seychelles), Dr Mohamed Samai (Sierra Leone), Dr Geoffrey Kenilorea and Mrs Nevalyn Laesango (Solomon Islands), Dr Lakshmi C Somatunga (Sri Lanka), Dr Nazik Hassan Babiker (Sudan), Mr Saifudinov Safar (Tajikistan), Dr Joao Martins (Timor-Leste), Dr Happy Kokou Agoudavi (Togo), Dr Silivia Tavite (Tokelau), Mr Sioape Kupu (Tonga), Dr Kumar Sundaraneedi (Trinidad and Tobago), Felise Manoa Afasene (Tuvalu), Dr Gerald Mutungi (Uganda), Dr Mary Mayige (United Republic of Tanzania), Dr Miskiya Mohamed (United Republic of Tanzania (Zanzibar)), Dr Maria Jose Rodriguez (Uruguay), Douglas Ngwele (Vanuatu), Dr Tran Quoc Bao (Viet Nam), Mr Tareq Ramahi (West Bank and Gaza Strip), Dr Namasiku Siyumbwa (Zambia). The authors would also like to thank the WHO staff worldwide who have assisted countries in the implementation of the STEPS surveys included in this study. This research also used information from the Health Surveys for epidemiological surveillance of the Under Secretariat of Public Health (Chile). The authors thank the Ministry of Health of Chile for allowing us to have the database. All results obtained from the study are the responsibility of the authors and do not compromise said institution. The authors would like to thank Dr Carlos Celis-Morales for his assistance in locating the Chilean data, Drs Gregore Mielke, Sotero Mengue and Inácio Silva for assistance in locating the Brazilian data, and Mr Christopher Hill for his assistance in checking The World Bank data.

Contributors FCB and TS conceptualised the study. MC and RG were responsible for STEPS and SAGE survey data acquisition and cleaning. TS and LG were responsible for data acquisition and cleaning from public archives. FCB, TS, SB, KW and LG developed the study methods. TS undertook the analysis and takes responsibility for the accuracy of the data. FCB, TS, SB, KW, LG and RG drafted and revised the manuscript. All authors approve the final version.

Funding TS, KW and SB are all funded by MRC programme grant (MC_ UU_12015/3). LG was supported by TIGTHAT, an MRC Global Challenges Project (MR/P024408/1)

Competing interests $M C, R G$ and FCB are staff members at WHO. The authors alone are responsible for the views expressed in this publication and they do not necessarily represent the decisions, policy, or views of WHO. All authors declare no competing interests.

Patient and public involvement Patients and/or the public were not involved in the design, or conduct, or reporting, or dissemination plans of this research.

Patient consent for publication Not required.

Ethics approval Ethical approval was obtained from appropriate national bodies for each survey.

Provenance and peer review Commissioned; externally peer reviewed.
Data availability statement Data are available in public, open access repositories. STEPS survey data are available on request at https://extranet.who. int/ncdsmicrodata/index.php/home. SAGE survey data are available on request at https://apps.who.int/healthinfo/systems/surveydata/index.php/catalog/sage/about. The NHANES survey data from the USA is available for download at https://wwwn. cdc.gov/nchs/nhanes/. KNHANES survey data from Rep. Korea are available after registration at https://knhanes.cdc.go.kr/knhanes/main.do. The PNAUM survey data from Brazil are available at http://www.ufrgs.br/pnaum/documentos/micro-dados/ microdados-adultos/view. The ENS survey data from Chile are cited as Department of Epidemiology, Ministry of Health, Chile with the website http://epi.minsal.cl/basesde-datos/.

Open access This is an open access article distributed in accordance with the Creative Commons Attribution 4.0 Unported (CC BY 4.0) license, which permits others to copy, redistribute, remix, transform and build upon this work for any purpose, provided the original work is properly cited, a link to the licence is given, and indication of whether changes were made. See: https://creativecommons.org/ licenses/by/4.0/.

\section{ORCID iDs}

Tessa Strain http://orcid.org/0000-0002-7086-1047

Katrien Wijndaele http://orcid.org/0000-0003-2199-798

Leandro Garcia http://orcid.org//0000-0001-5947-2617

Regina Guthold http://orcid.org/0000-0003-3073-6468

Soren Brage http://orcid.org/0000-0002-1265-7355

Fiona C Bull http://orcid.org/0000-0001-8035-4973

\section{REFERENCES}

1 Bull FC, Al-Ansari SS, Biddle S, et al. World Health Organization 2020 guidelines on physical activity and sedentary behaviour. Brit J Sport Med 2020. doi: 10.1136/ bjsports-2020-102955.

2 World Health Organization. Global Action Plan on Physical Activity 2018-2030: more active people for a healthier world. Geneva: World Health Organization, 2018.

3 World Health Organization. Global recommendations on physical activity for health. Geneva: World Health Organisation, 2010.

4 Guthold R, Stevens GA, Riley LM, et al. Worldwide trends in insufficient physical activity from 2001 to 2016: a pooled analysis of 358 population-based surveys with 1.9 million participants. Lancet Glob Health 2018;6:e1077-86.

5 Samitz G, Egger M, Zwahlen M. Domains of physical activity and all-cause mortality: systematic review and dose-response meta-analysis of cohort studies. Int J Epidemiol 2011;40:1382-400.

$6 \mathrm{Ng} \mathrm{SW}$, Norton EC, Popkin BM. Why have physical activity levels declined among Chinese adults? findings from the 1991-2006 China health and nutrition surveys. Soc Sci Med 2009:68:1305-14.

7 Katzmarzyk PT, Mason C. The physical activity transition. J Phys Act Health 2009:6:269-80.

8 Ng SW, Popkin BM. Time use and physical activity: a shift away from movement across the globe. Obes Rev 2012;13:659-80.

9 Lear SA, Hu W, Rangarajan S, et al. The effect of physical activity on mortality and cardiovascular disease in 130000 people from 17 high-income, middle-income, and low-income countries: the PURE study. Lancet 2017;390:2643-54.

10 Van Tuyckom C. Macro-environmental factors associated with leisure-time physical activity: a cross-national analysis of EU countries. Scand J Public Health 2011;39:419-26.

11 Götschi T, Tainio M, Maizlish N, et al. Contrasts in active transport behaviour across four countries: how do they translate into public health benefits? Prev Med 2015;74:42-8.

12 Mielke GI, da Silva ICM, Kolbe-Alexander TL, et al. Shifting the physical inactivity curve worldwide by closing the gender gap. Sports Med 2018;48:481-9.

13 Bauman AE, Reis RS, Sallis JF, et al. Correlates of physical activity: why are some people physically active and others not? Lancet 2012;380:258-71.

14 Bauman A, Ma G, Cuevas F, et al. Cross-national comparisons of socioeconomic differences in the prevalence of leisure-time and occupational physical activity, and active commuting in six Asia-Pacific countries. J Epidemiol Community Health 2011;65:35-43.

15 Mitáš J, Cerin E, Reis RS, et al. Do associations of sex, age and education with transport and leisure-time physical activity differ across 17 cities in 12 countries? Int $J$ Behav Nutr Phys Act 2019;16:121.

16 Werneck AO, Baldew S-S, Miranda JJ, et al. Physical activity and sedentary behavior patterns and sociodemographic correlates in 116,982 adults from six South American countries: the South American physical activity and sedentary behavior network (SAPASEN). Int J Behav Nutr Phys Act 2019;16:68.

17 Strain T, Fitzsimons C, Foster C, et al. Age-related comparisons by sex in the domains of aerobic physical activity for adults in Scotland. Prev Med Rep 2016;3:90-7.

18 Bélanger M, Townsend N, Foster C. Age-related differences in physical activity profiles of English adults. Prev Med 2011;52:247-9.

19 World Health Organization. Global physical activity surveillance. Available: https:// www.who.int/ncds/surveillance/steps/GPAQ/en/ 
20 World Health Organization. STEPwise approach to noncommunicable disease risk factor surveillance (STEPS). Available: https://www.who.int/ncds/surveillance/steps/ riskfactor/en/

21 World Health Organization. WHO Study on global AGEing and adult health (SAGE). Available: https://www.who.int/healthinfo/sage/en/

22 The World Bank. World Bank country and lending groups (for fiscal year 2020), 2020 Available: https://datahelpdesk.worldbank.org/knowledgebase/articles/906519world-bank-country-and-lending-groups

23 United Nations Department of Economic and Social Affairs. Population dynamics: world population prospects 2020, 2020. Available: https://population.un.org/wpp/

24 Bull FC, Maslin TS, Armstrong T. Global Physical Activity Questionnaire (GPAQ): nine country reliability and validity study. J Phys Act Health 2009;6:790-804.

25 Trinh OTH, Nguyen ND, van der Ploeg HP, et al. Test-retest repeatability and relative validity of the Global Physical Activity Questionnaire in a developing country context. J Phys Act Health 2009;6 Suppl 1:S46-53.

26 Wanner M, Hartmann C, Pestoni G, et al. Validation of the Global Physical Activity Questionnaire for self-administration in a European context. BMJ Open Sport Exerc Med 2017;3:e000206.

27 Dugas LR, Bovet $P$, Forrester $T E$, et al. Comparisons of intensity-duration patterns of physical activity in the US, Jamaica and 3 African countries. BMC Public Health 2014; 14:882

28 Hoos T, Espinoza N, Marshall S, et al. Validity of the Global Physical Activity Questionnaire (GPAQ) in adult Latinas. J Phys Act Health 2012;9:698-705.

29 Hamilton NE, Ferry M. ggtern: ternary diagrams using ggplot2. J Stat Softw 2018;87:1-17.

30 Schöley J, Kashnitsky I. tricolore: a flexible color scale for ternary compositions R package version 1.2.1, 2019. Available: https://CRAN.R-project.org/package=tricolore

31 Guthold R, Louazani SA, Riley LM, et al. Physical activity in 22 African countries: results from the World Health Organization STEPwise approach to chronic disease risk factor surveillance. Am J Prev Med 2011;41:52-60.

$32 \mathrm{Ng} \mathrm{N}$, Hakimi M, Van Minh H, et al. Prevalence of physical inactivity in nine rural indepth health and demographic surveillance systems in five Asian countries. Glob
Health Action 2009;2. doi:10.3402/gha.v2i0.1985. [Epub ahead of print: 28 Sep 2009].

33 United Nations. Sustainable Development Goals, 2020. Available: https://www.un. org/sustainabledevelopment/sustainable-development-goals/

34 Bauman A, Allman-Farinelli M, Huxley R, et al. Leisure-time physical activity alone may not be a sufficient public health approach to prevent obesity--a focus on China. Obes Rev 2008;9 Suppl 1:119-26.

35 Del Duca GF, Nahas MV, Garcia LMT, et al. Active commuting reduces sociodemographic differences in adherence to recommendations derived from leisuretime physical activity among Brazilian adults. Public Health 2016;134:12-17.

36 Coenen P, Huysmans MA, Holtermann A, et al. Do highly physically active workers die early? A systematic review with meta-analysis of data from 193696 participants. Br J Sports Med 2018;52:1320-6.

37 Wijndaele K, DE Bourdeaudhuij I, Godino JG, et al. Reliability and validity of a domain-specific last 7-d sedentary time questionnaire. Med Sci Sports Exerc 2014;46:1248-60.

38 Bui TV, Blizzard CL, Luong KN, et al. Physical activity in Vietnam: estimates and measurement issues. PLoS One 2015;10:e0140941.

39 Lindsay T, Westgate K, Wijndaele K, et al. Descriptive epidemiology of physical activity energy expenditure in UK adults (the Fenland study). Int J Behav Nutr Phys Act 2019:16:126.

40 Barnett J, Nigg C, De Bourdeaudhuij I, et al. Effect of item order on physical activity estimates using the IPAQ. Californian J Health Promot 2007;5:23-9.

41 Roberts D, Townsend N, Foster C. Use of new guidance to profile 'equivalent minutes' of aerobic physical activity for adults in England reveals gender, geographical, and socio-economic inequalities in meeting public health guidance: A cross-sectional study. Prev Med Rep 2016:4:50-60.

42 Anjana RM, Pradeepa R, Das AK, et al. Physical activity and inactivity patterns in India - results from the ICMR-INDIAB study (Phase-1) [ICMR-INDIAB-5]. Int J Behav Nutr Phys Act 2014;11:26.

43 World Health Assembly. WHA71.6 WHO global action plan on physical activity 2018-2030, 2018 